\title{
Educação física e aulas remotas: um olhar para o trabalho com alunos com deficiência em escolas do Rio Grande do Sul
}

\author{
Physical education and remote classes: a look at work \\ with disabled students in Rio Grande do Sul
}

\section{Educación física y clases remotas: una mirada al trabajo con estudiantes discapacitados en las escuelas en Rio Grande do Sul}

\author{
iD (9) Caroline Maciel da Silva \\ Universidade Federal do Rio Grande do Sul, Porto Alegre, Rio Grande do Sul, Brasil. \\ E-mail: carolinemaciel78@gmail.com \\ Roseli Belmonte Machado \\ Universidade Federal do Rio Grande do Sul, Porto Alegre, Rio Grande do Sul, Brasil. \\ E-mail: robelmont@yahoo.com.br \\ Denise Grosso da Fonseca \\ Universidade Federal do Rio Grande do Sul, Porto Alegre, Rio Grande do Sul, Brasil. \\ E-mail: dgf.ez@terra.com.br
}

\begin{abstract}
Resumo: Este artigo aborda a Educação Física no período de distanciamento social e a inclusão escolar. Caracteriza-se por um estudo qualitativo descritivo exploratório que tem por objetivo compreender como é contemplado o ensino remoto da Educação Física para os alunos com deficiência. Foi realizada uma pesquisa com 43 docentes através de envio de questionário. Constatam-se alterações e adaptações no currículo e nas aulas, dificuldades de acesso a tecnologias e a diminuição do contato entre professores e alunos. Entende-se que a manutenção do vínculo/aprendizagens, a capacitação docente e o reconhecimento deste trabalho são demandas importantes neste processo. Ressalta-se que as
\end{abstract}


diferenças devem estar presentes nos contextos escolares, potencializando o desenvolvimento humano.

Palavras-chave: Educação física. Inclusão escolar. Ensino Remoto.

Abstract: This article addresses Physical Education in the period of social distance and school inclusion. It is characterized by a qualitative descriptive exploratory study that aims to understand how remote teaching of Physical Education is contemplated for disabled students. A survey was conducted with 43 teachers by sending a questionnaire. There are changes and adaptations in the curriculum and classes, difficulties in accessing technologies and decreased contact between teachers and students. It is understood that maintaining the bond / learning, teacher training and recognition of this work are important demands in this process. It is emphasized that differences must be present in school contexts, enhancing human development.

Keywords: Physical education. School inclusion. Remote Teaching.

Resumen: Este artículo aborda la Educación Física en el período de distancia social y la inclusión escolar. És un estudio exploratorio descriptivo cualitativo, con la intención de comprender cómo se contempla la enseñanza a distancia de Educación Física para los estudiantes discapacitados. Se realizó una encuesta a 43 profesores mediante el envío de un cuestionario. Hay cambios y adaptaciones en el plan de estudios y las clases, dificultades para acceder a las tecnologías y menor contacto entre profesores y alumnos. Se entiende que mantener el vínculo/ aprendizaje, la formación docente y el reconocimiento de este trabajo son demandas importantes en este proceso. Se enfatiza que las diferencias deben estar presentes en los contextos escolares, potenciando el desarrollo humano.

Palabras clave: Educación física. Inclusión escolar. Enseñanza remota.

Submetido em: 06-10-2020

Aceito em: 18-02-2021 
ducação física e aulas remotas: um olhar para o trabalho com alunos com deficiência...

\section{Introdução}

Estudantes espalhados pelo mundo todo foram afetados pelo fechamento das escolas durante a pandemia do Coronavírus. $O$ ano letivo de 2020 nem bem começou e fomos surpreendidos pela suspensão de atividades com contato direto entre as pessoas, dentre as quais se colocam as aulas presenciais, como forma de minimizar a proliferação da COVID-19. Com isso, a demanda que tem se apresentado é repensar/recriar/reaprender/reinventar uma infinidade de situações na vida cotidiana.

Tem se discutido, no âmbito federal, estadual e municipal, medidas que busquem por estratégias para dar continuidade aos processos de ensino neste período de distanciamento social. Uma dessas estratégias é o ensino remoto, aplicada em diversas cidades do país. Uma forma que procura dar continuidade ao que vinha sendo desenvolvido pelas instituições escolares, mas, agora, no âmbito das casas dos estudantes.

Nesse contexto, estamos nós, professores e professoras, promovendo adaptações nas organizações curriculares e na maneira com que essas são ensinadas aos alunos e alunas, numa tentativa de prosseguir com os processos de ensino para que todos sejam contemplados. Uma tarefa que se mostra difícil e controversa na medida em que compreendemos a imensa heterogeneidade dos alunos e as desigualdades sociais e econômicas da sociedade brasileira, que se transformam em grandes barreiras para o acesso ao ensino de forma remota. Sobre a heterogeneidade dos alunos, nos colocamos a destacar a situação daqueles que hoje são nomeados como alunos de inclusão no processo de ensino remoto. Para o acesso, permanência e desenvolvimento de suas aprendizagens de forma qualificada, as instituições precisam, muitas vezes, realizar adaptações importantes em suas organizações curriculares, metodologias, condições estruturais etc. Nesse sentido, nos perguntamos: como está sendo o processo de ensino e aprendizagem do componente curricular Educação Física dos alunos com deficiência durante a realização do ensino remoto? 
ducação física e aulas remotas: um olhar para o trabalho com alunos com deficiência...

Caroline Maciel da Silva • Roseli Belmonte Machado • Denise Grosso da Fonseca

A presente problematização faz parte de uma pesquisa ${ }^{1}$ aprovada em comitê de ética de uma universidade, desenvolvida com o objetivo principal de compreender o modo como a Educação Física escolar, nesse Estado, tem se posicionado no cenário das aulas remotas. Como desdobramento investigativo, se propõe a compreender como é contemplado o ensino remoto da Educação Física para os alunos com deficiência, também considerados de inclusão, o qual é o foco apresentado neste artigo.

\section{Aspectos metodológicos}

Diante do que foi exposto nas linhas introdutórias, situamos que o objetivo deste estudo está em compreender como é contemplado o ensino remoto da Educação Física para os alunos com deficiência. Este estudo caracteriza-se como qualitativo do tipo descritivo exploratório, envolvendo entrevistas com pessoas que tiveram experiências práticas com o problema pesquisado. Essa ação é realizada, especialmente, quando o tema escolhido é pouco explorado (GIL, 2008). Com o intuito de refletir sobre todo esse novo processo de ensino e aprendizagem - novo no sentido de que são tempos novos, que exigem novas atitudes, novas ferramentas e novos planejamentos - foi organizada a pesquisa de âmbito estadual gaúcho, com docentes das redes de ensino estaduais, municipais e privadas.

Durante os meses de março e abril de 2020, foram convidados a participar da pesquisa professores e professoras de Educação Física que realizaram um curso de extensão² promovido por uma universidade do Rio Grande do Sul. A pesquisa foi realizada pelo Google Forms, dando atenção aos cuidados éticos de pesquisa e anexando termo de consentimento livre e esclarecido. Após esse movimento, outros professores foram convidados, obedecendo aos seguintes critérios de seleção: 1) ser professor que atua na

\footnotetext{
1 A informação completa da pesquisa está suprimida para fins de avaliação dos pares. $2 \mathrm{~A}$ informação completa da pesquisa está suprimida para fins de avaliação dos pares.
} 
ducação física e aulas remotas: um olhar para o trabalho com alunos com deficiência... Caroline Maciel da Silva • Roseli Belmonte Machado • Denise Grosso da Fonseca

Educação Básica; 2) estar trabalhando no momento de distanciamento social. No total participaram 43 professores e professoras.

Nogueira e Resende (2020) apontam que, no Brasil, não há pesquisas sobre longos períodos sem aula e sua relação com a aprendizagem:

[...] apesar de não contarmos com pesquisas desse tipo no Brasil, suas conclusões fazem todo o sentido diante do que se conhece sobre as desigualdades educacionais em nosso país. [...] Nesse contexto, o distanciamento temporal em relação a esse "universo" tende a ter efeitos mais perversos do que para os demais grupos, podendo, frequentemente, levar ao abandono do projeto de estudos e à evasão (NOGUEIRA E RESENDE, 2020, p. 1)

Nessa perspectiva, os autores supracitados enfatizam os efeitos da desigualdade social na escolaridade de crianças e jovens oriundos de camadas populares, fato que ganha outros matizes no contexto do distanciamento social com suas consequentes alternativas de ensino e aprendizagem. Dentre as inúmeras preocupações desse cenário tão desconhecido e reforçado pelas desigualdades sociais que vivemos em nosso país, é de extrema importância e relevância que se realizem estudos que articulem os temas Educação Física, distanciamento social e suas reverberações na vida dos estudantes de inclusão. Em nossa compreensão, esse público, por vezes, fica à margem de muitas preocupações pedagógicas.

Desse modo, com o intuito de dar visibilidade a esse propósito investigativo, esta pesquisa se debruça sobre as seguintes questões respondidas pelos docentes: 1) Rede de atuação dos professores e professoras; 2) Cidade de atuação dos professores e professoras; 3) Se os professores e professoras estão realizando atendimento ao alunado de inclusão; 4) As aulas para os alunos e alunas de inclusão são as mesmas dos demais? 5) Quais atividades você realiza com os alunos e alunas considerados de inclusão, neste momento? 
ducação física e aulas remotas: um olhar para o trabalho com alunos com deficiência... Caroline Maciel da Silva • Roseli Belmonte Machado • Denise Grosso da Fonseca

Esse direcionamento da pesquisa nos ajudou a compreender como o professorado de Educação Física está lidando com as questões do distanciamento dos alunos de forma geral e quais as estratégias utilizadas com alunos e alunas de inclusão. Para tanto, apresentamos essa discussão nas duas seções subsequentes chamadas de: "Tecnologias, Ensino Remoto e Inclusão" e "Práticas escolares de Educação Física e o ensino remoto".

\section{Tecnologias, ensino remoto e inclusão}

O trabalho docente, como conhecemos, está sendo constantemente atravessado pela tecnologia. Isso traz a possibilidade de um novo modo de ensinar, de aprender e, por que não, de viver. O desafio dos alunos e alunas, dos professores e professoras, é acompanhar essas mudanças e da maneira mais urgente. Contudo, surge uma questão acerca do tema: será que todos conseguirão acompanhar essas mudanças e com a urgência em que ela se mostra? Segundo Chizzotti

[...] é um desafio que cada geração está obrigada a realizar. As tecnologias da informação e comunicação atualizam, pois, a recriação da vida humana. Embora seja um tema recorrente na história, é preciso ter presente: as tecnologias da comunicação suscitam provocações nunca antes imaginadas (CHIZZOTTI, 2020, p. 490).

A exclusão digital é uma forma de exclusão social, logo se torna uma questão de políticas públicas. Para Loureiro e Lopes (2015), estar incluído digitalmente é condição mínima para participação em uma sociedade em rede e para que estejamos conectados a outras formas de trabalho, de relacionamento e de participação política, social, cultural e econômica.

Dessa forma, assegurar que todos tenham acesso ao mundo digital é condição necessária, embora não suficiente, para garantir 
ducação física e aulas remotas: um olhar para o trabalho com alunos com deficiência...

Caroline Maciel da Silva • Roseli Belmonte Machado • Denise Grosso da Fonseca

condições de possibilidade para que em um futuro próximo tenhamos, em diferentes escalas de participação, uma população conectada e acessível às capturas digitais (LOUREIRO e LOPES, 2015, p. 362).

Vislumbrando opções para equacionar a suspensão das aulas devido à pandemia, o Estado do Rio Grande do Sul, assim como outros estados brasileiros, aderiu à forma remota como ferramenta de ensino no período de distanciamento social e enfrentamento à Covid-19 a partir de junho de 20203. Esse sistema de ensino está utilizando a plataforma Classroom, oferecida pela Google for Education ${ }^{4}$, e dá outras providências, como aulas programadas, atividades digitais e protocolos específicos em caso de retorno das aulas presenciais.

As aulas remotas são a prioridade do plano de retomada e alicerce fundamental do modelo híbrido - uso de tecnologia e disponibilização de material aos pais ou responsáveis com dificuldades de acesso à internet - que será implementado (RIO GRANDE DO SUL, 2020). Contudo, sabemos que são muitos os entraves para que o ensino remoto aconteça de forma justa e equalitária. São alguns deles: o acesso de conectividade à internet, a obtenção de dispositivos que permitam o acesso a essa plataforma de ensino, a disponibilidade das famílias, a criação de currículos adaptados a essa nova forma de aprendizagem e a atenção a todos os estudantes.

Dentre as situações citadas, uma tem nos preocupado sobremaneira, que é a atenção a todos os estudantes, especificamente, a situação dos alunos com deficiência, pois, de um modo amplo, podemos dizer que, historicamente, esses sujeitos vivenciam distintos processos que os excluem de vínculos sociais e educacionais. Compreendemos que, em se tratando dos alunos e alunas de inclusão, o desafio é ainda maior. Muitos deles dependem do apoio e da parceria da família para acessar e realizar as atividades educativas propostas pelos professores e professoras como um

$\overline{3 \text { Informaç̃es no site }}$ https://estado.rs.gov.br/upload/arquivos//distanciamento-controlado-educacao.pdf. Acesso em 30 jul 2020. 4 Disponível em: https://edu.google.com/?modal_active=none. Acesso em 30 jul. 2020. 
ducação física e aulas remotas: um olhar para o trabalho com alunos com deficiência...

todo e pelos de Educação Física. E, além disso, há outra dificuldade, pois muitos desses alunos e alunas não conseguem realizar seus atendimentos extraescolares em instituições especializadas, fato que pode alterar o aproveitamento educacional.

Quando uma família faz a matrícula de seu filho na escola regular, ela está lutando pelo direito da inclusão. A Lei n 13.146, que institui a Lei Brasileira de Inclusão da Pessoa com Deficiência - Estatuto da Pessoa com Deficiência (BRASIL, 2015), no capítulo IV, do Direito à Educação, no artigo 27, coloca que:

[...] a educação constitui direito da pessoa com deficiência, assegurado sistema educacional inclusivo em todos os níveis e aprendizado ao longo de toda a vida, de forma a alcançar o máximo desenvolvimento possível de seus talentos e habilidades físicas, sensoriais, intelectuais e sociais, segundo suas características, interesses e necessidades de aprendizagem (BRASIL, 2015, artigo27).

Importante destacar que a educação especial não é um nível de ensino, mas sim uma modalidade. A partir da Política Nacional de Educação Especial na Perspectiva da Educação Inclusiva (BRASIL, 2007), ficou estabelecido que seu público-alvo são estudantes com deficiência, com transtornos globais do desenvolvimento e altas habilidades ou superdotação.

Na perspectiva da educação inclusiva, a educação especial passa a integrar a proposta pedagógica da escola regular, promovendo o atendimento aos estudantes com deficiência, transtornos globais do desenvolvimento e altas habilidades/superdotação. Nestes casos e em outros, como os transtornos funcionais específicos, a educação especial atua de forma articulada com o ensino comum, orientando para o atendimento desses estudantes (BRASIL, 2007, p. 11).

O aluno deve receber atendimento educacional especializado quando incluído na escola regular. No entanto, devido às carac- 
ducação física e aulas remotas: um olhar para o trabalho com alunos com deficiência... Caroline Maciel da Silva • Roseli Belmonte Machado • Denise Grosso da Fonseca

terísticas do trabalho escolar, isso nem sempre se manifesta de maneira tão clara. Nem sempre é fácil se abrir para novas práticas. Mesmo que se queira, muitas vezes, a trilha para um novo caminho está dificultada pela falta de recursos nas escolas. Em muitas delas, não há um espaço para que sejam construídas salas especializadas, não há materiais ou mesmo recursos para confecção desses materiais, não há instalados computadores/softwares que tenham sido desenvolvidos para os alunos e alunas de inclusão, o que indicaria que a tecnologia já era um entrave antes mesmo do ensino remoto acontecer.

A Educação Física escolar é uma grande aliada para o desenvolvimento físico, social e cognitivo dos alunos e alunas de inclusão. Segundo Nacif et al (2016), no aspecto físico, a Educação Física pode favorecer o desenvolvimento da consciência corporal, de habilidades e capacidades, bem como reflexões sobre as possibilidades de movimento de cada aluno. No âmbito psicológico, há a meIhora da autoestima, a diminuição dos sintomas depressivos e do nível de ansiedade. Por fim, no contexto social, a possibilidade de o aluno com deficiência participar das atividades com os colegas, favorece as relações afetivas além de contribuir com o respeito pelas diferenças.

Quando estudantes diferentes participam conjuntamente, as atividades ficam mais ricas, mais desafiantes, porque abrangem um número maior de experiências. A criação de um ambiente de aprendizagem, que viva a diferença, favorece não somente as atividades físicas e práticas desportivas, mas principalmente o convívio social e o desenvolvimento de posturas e atitudes de valorização e de respeito às diferenças. Contudo, temos considerado que a potência inclusiva que reside no trabalho desenvolvido na Educação Física escolar, além de outros entraves, hoje conta com os impedimentos advindos da falta de acesso dos alunos ao ensino remoto. Nem todos têm acesso a tecnologias, além de, por vezes, não contarem com apoio físico e humano em seus lares.

Todos esses apontamentos nos remetem a pensar e a problematizar as relações de in/exclusão no espaço escolar. Concordamos 
ducação física e aulas remotas: um olhar para o trabalho com alunos com deficiência... Caroline Maciel da Silva • Roseli Belmonte Machado • Denise Grosso da Fonseca

com Lopes (2007), que aponta que "inclusão e exclusão estão articuladas dentro de uma mesma matriz epistemológica, política, cultural e ideológica" (LOPES, 2001, p. 11), incluímos e excluímos em nossas operações cotidianas. Para compreender essa discussão, é preciso colocar que os processos de inclusão e de exclusão possuem relação com aquilo que a sociedade tem compreendido como quem precisa ser incluído e aquele que já está numa posição de maioria, ou seja, não precisa ser incluído, pois está num espaço visto como normal para ele.

A busca por uma ordem, a partir do advento da Modernidade, instituiu normas que ainda classificam, comparam, avaliam e, portanto, incluem e excluem os distintos sujeitos de acordo com as normas que cotidianamente vão se estabelecendo como válidas. $\mathrm{Na}$ esteira dos trabalhos desenvolvidos por Foucault (2008), destacamos que essas normas têm origem numa espécie de biopoder - um poder direcionado para gerir a vida - em operações de normação e de normalização. Operações de normação são conexas a mecanismos disciplinares de poder que avaliam e classificam a partir de um modelo considerado ideal, um "normal". Já as operações de normalização são aquelas que estabelecem quem é "normal" ou "anormal" a partir de um conjunto de regularidades que se repetem e, por estatística, designam o que é e como é a maioria, a média, o normal e a norma. O estabelecimento dessa ordem, a partir da Modernidade, é o que possibilita dizer quem são os normais e quem são os anormais - aqueles que são o objeto de inclusão, ou seja, aqueles que precisam ser normalizados, entrar na norma.

Todavia, o processo de normalização - de trazer para a norma por uma comparação estatística - ou o processo de normação - que considera um modelo de comparação entre os sujeitos -, ao normalizarem os sujeitos, colocarem nas instituições por ações ditas inclusivas, carregam em si práticas de exclusão. Por exemplo, quando colocamos todos dentro de mesmos espaços e instituições, como a instituição escolar, nem sempre é garantido o tratamento equitativo a todos. Por vezes, o que se estabelece são 
ducação física e aulas remotas: um olhar para o trabalho com alunos com deficiência...

Caroline Maciel da Silva • Roseli Belmonte Machado • Denise Grosso da Fonseca

processos que, ao normalizar os distintos sujeitos, provocam práticas excludentes. Por isso, consideramos que, agora, inclusão e exclusão pertencem a uma mesma matriz epistemológica.

Na escola, observamos sujeitos que habitam o mesmo espaço de outros, mas, como dissemos, nem sempre participam de todos os processos de ensino e de aprendizagem. Isso, tanto pela falta de recursos - incluindo a falta de recursos tecnológicos que apontamos nesta seção -, por qualificação docente ineficaz ou por organizações curriculares excludentes, dentre outras questões.

Nesse sentido, levantamos essa problematização, pois compreendemos que, também no ensino remoto, estejam acontecendo processos de exclusão em relação aos alunos que eram considerados incluídos na escola, principalmente os alunos com deficiência.

\section{Práticas escolares de educação física e inclusão no ensi- no remoto}

Toda a comunidade escolar - pessoal docente, técnicos, alunos, famílias - está tendo que readequar as suas práticas educativas em função da pandemia da COVID-19 e a nova realidade educacional que se impôs pelo distanciamento social. Destaca-se, nesse contexto, a rapidez com que foi necessária essa readequação. Para mostrar um pouco dessa realidade, apresentamos alguns dados da pesquisa realizada.

Participaram da pesquisa quarenta e três professores e professoras, oriundos de diversas cidades gaúchas. Esses docentes, em sua maioria, lecionam em escolas públicas. Desses, vinte e sete (27) trabalhavam com alunos com deficiência. Podemos entender que há um crescimento no número de alunos e alunas de inclusão nas turmas regulares de ensino. Segundo o INEP, o Censo Escolar $2018^{5}$ revela avanços na educação especial. O número de matrícu-

5 Dados disponíveis em http://portal.inep.gov.br/artigo/-/asset_publisher/B4AQV9zFY7Bv/content/censo-escolar-2018-revela-crescimento-de-18-nas-matriculas-em-tempo-integral-no-ensino-medio/21206. Acesso em 31 jul. 2020. 
ducação física e aulas remotas: um olhar para o trabalho com alunos com deficiência... Caroline Maciel da Silva • Roseli Belmonte Machado • Denise Grosso da Fonseca

las de alunos com deficiência, transtornos globais do desenvolvimento e/ou altas habilidades/superdotação em classes comuns incluídos - ou em classes especiais exclusivas, chegou a 1,2 milhão em 2018, um aumento de 33,2\% em relação a 2014.

Sobre a realização de atividades diferenciadas a esses alunos, dos 27 que possuíam alunos de inclusão, dezenove (19) informaram que não fazem atividades diferenciadas para os alunos de inclusão e oito (8) docentes responderam que fazem atividades diferenciadas para os alunos de inclusão. A maior parte do professorado de Educação Física, ao enviar propostas diferenciadas para os alunos de inclusão, preferem as atividades que favoreçam o movimento do corpo, como alongamentos, passos de dança, atividades lúdicas, brincadeiras e de socialização, conforme extrato abaixo:

As que favoreçam o movimento e também a atenção (dança) (PROFESSORJ11), alongamentos e brincadeiras (PROFESSOR L13), as aulas são colaborativas e perceptivas (PROFESSOR BB29), [...] proponho brincadeiras, construção de brinquedos em família e exploração de matérias diversos (PROFESSOR HH 35).

A Educação Física, como componente curricular obrigatório, tem a responsabilidade de se colocar como um importante elemento na Educação Inclusiva. A escola é um espaço de desenvolvimento para além do cognitivo, mas também de socialização e enriquecimento do aluno. Segundo Chicon (2013), todas as diferenças humanas são normais e, portanto, a aprendizagem deve ajustar-se às necessidades de cada criança.

Existe a imperiosa necessidade de mudança da perspectiva social baseada na incapacidade da criança para a perspectiva centrada em seu potencial e que modificações de programas de estudo, metodologias de ensino, sistemas de avaliação e adaptação em mobiliário devem ser realizados quando se fizerem necessários para atender as peculiaridades de quem aprende (CHICON, 2013, p. 16). 
ducação física e aulas remotas: um olhar para o trabalho com alunos com deficiência...

Caroline Maciel da Silva • Roseli Belmonte Machado • Denise Grosso da Fonseca

Cada prática corporal propicia ao sujeito o acesso a uma dimensão de conhecimentos e de experiências que ele não teria de outro modo. A vivência da prática é uma forma de gerar um tipo de conhecimento muito particular e insubstituível e, para que ela seja significativa, é preciso problematizar, desnaturalizar e evidenciar a multiplicidade de sentidos e significados que os grupos sociais conferem às diferentes manifestações da cultura corporal de movimento.

Na sistematização do ensino remoto no Rio Grande do Sul, as atividades de ensino, segundo os colaboradores, são enviadas para um setor especifico da escola - Sala de Recursos, direção da escola - ou enviadas pelo Google Classroom $^{6}$ e, na fala dos docentes, adaptadas com um menor grau de dificuldade, quando comparada com as atividades enviadas ao restante dos alunos. Todavia, pudemos verificar que a falta de acesso à internet e, consequentemente, às plataformas estabelecidas pela Secretaria de Educação do RS são um problema enfrentado pelas famílias. Isso é demonstrado nas falas a seguir:

[...] a minoria tem condições de pagar por banda larga e os computadores e/ou celulares têm pouca memória e/ou recursos. (PROFESSOR C4, J11 e HH35).

Fazer com que as atividades cheguem aos alunos devido à falta de acesso à internet. (PROFESSOR DD31).

[...] alunos terem acesso as atividades, minha escola é e uma comunidade carente que grande parte não tem acesso ou até mesmo divide o celular com uma internet fraca entre seus irmãos para acessar as atividades (PROFESSOR HH 35).

$O$ acesso dos estudantes e por consequência a feitura das tarefas (PROFESSOR MM 40).

Muitas famílias não possuem equipamentos eletrônicos que comportem as versões disponibilizadas. Portanto, para que os alunos e alunas de inclusão acessem as tarefas propostas para eles,

6 Ferramenta disponibilizada por algumas prefeituras e pelo Governo do Estado do Rio Grande do Sul, para auxiliar na distribuição de tarefas online. 
ducação física e aulas remotas: um olhar para o trabalho com alunos com deficiência... Caroline Maciel da Silva • Roseli Belmonte Machado • Denise Grosso da Fonseca

algumas iniciativas foram tomadas por parte das escolas e dos professores e professoras, tais como: 1) manter o vínculo com as famílias através de contato telefônico, via WhatsApp e vídeos postados nesta plataforma; 2 ) criação de grupos de WhatsApp, sendo alimentado com atividades pelos docentes ou a direção das escolas; 3) envolver a direção e orientação escolar quando do não retorno das atividades; 4) adaptação de atividades para os alunos e alunas com deficiência; 5) disponibilização de material impresso para que seja retirado diretamente na escola.

A criação de novas formas de comunicação e realização das tarefas escolares que foram impostas de maneira tão abrupta pelo distanciamento social nos faz pensar no vínculo e no envolvimento que, de certa maneira, pode ter se perdido na não possibilidade de aulas presenciais.

Mattos (2008) menciona a importância da afetividade na aprendizagem escolar de alunos com deficiência, transtornos globais de desenvolvimento (TGD) e altas habilidades/superdotação:

[...] a inclusão das crianças excluídas carece de ser feita pelo domínio afetivo, mostrando que é possível ter sucesso e aprender, que é possível construir o saber tendo como base o conhecimento trazido por ela e pela comunidade local (MATTOS, 2008, p. 52)

Compreendemos que a participação em conjunto de todos os profissionais de educação envolvidos no processo de aprendizagem e a preocupação de envolver todos os estudantes de uma forma participativa nas aulas remotas podem ser aliadas à ação docente e ferramenta para a inclusão dos alunos e alunas. Outra ferramenta eletrônica muito utilizada pelas escolas para a comunicação com os estudantes e suas famílias é o aplicativo de mensagens WhatsApp. Bottentuit Junior e Albuquerque (2016) referem-se ao aplicativo WhatsApp como uma ferramenta que possui um conjunto vasto de possibilidade de comunicação no contexto educativo como "um canal direto entre professor-aluno, ou mes- 
ducação física e aulas remotas: um olhar para o trabalho com alunos com deficiência... Caroline Maciel da Silva • Roseli Belmonte Machado • Denise Grosso da Fonseca

mo, com todos os alunos de uma turma de uma só vez (caso estejam organizados num grupo); uma forma de ampliar a comunicação de maneira rápida e criar novos espaços de aprendizagem" (BOTTENTUIT JUNIOR E ALBUQUERQUE, 2000, p. 321). A maioria dos professores pesquisados menciona usar esse aplicativo como forma de comunicação e/ou distribuição das tarefas escolares. Um número significativo e que se justifica por ser uma ferramenta que parece acessível para toda a comunidade escolar.

O ensino remoto pode ser uma possibilidade de ensino para este momento de distanciamento social, mas, conforme Shimazaki, Menegassi e Fellini (2020, p. 8)

[...] se apresentaria como um sistema de ensino distante da realidade de muitas crianças e jovens, assim como o acesso aos conhecimentos científicos, necessários ao seu desenvolvimento psíquico. Esse modelo moderno de ensino exclui aqueles que não conseguem se adequar às necessidades básicas que a tecnologia exige (SHIMAZAKI, MENEGASSI E FELLINI, 2020, p. 8).

Corroborando os autores supracitados, Melca e Ferreira (2005) mencionam que a Internet, embora seja uma ferramenta de crescimento e expansão social maior que todas as outras mídias modernas, ainda é um recurso tecnológico que exclui muitas pessoas. "E isso ainda fica mais evidenciado quando existe alguma necessidade especial por parte do usuário, que demande uma especificidade maior na forma de utilização" (MELCA E FERREIRA, 2005, p. 5). Também concordamos com Chizzotti (2020) quando ele menciona que a humanidade tem o direito de obter informações fidedignas, acesso à tecnologia em todas as suas formas. Entretanto, se essa mesma tecnologia não favorecer a todos, ela se torna sem sentido.

Ao tratarmos das especificidades da Educação Física na perspectiva da educação inclusiva, na modalidade ensino remoto, se considera que, para além das dificuldades já enfrentadas no cotidiano das escolas, outras se apresentaram. Em primeiro lugar, estão as dificuldades de acesso a tecnologias que propiciam essa 
ducação física e aulas remotas: um olhar para o trabalho com alunos com deficiência...

modalidade de ensino e que faz com que os alunos não acessem as aulas e, em segundo lugar, a diminuição do contato entre professores e alunos, o que dificulta o favorecimento de processos inclusivos, na medida em que a potência de estar com o outro e de viver a diferença é impossibilitada pela distância física.

\section{Como caminhar deixando alguns para trás?}

A realidade educacional que estamos vivendo traz muitas angústias e limitações à prática pedagógica do professorado de Educação Física do Rio Grande do Sul. Não desconsiderando a importância das alterações e adaptações de currículo, é fundamental pensar em como vamos mobilizar possibilidades de acesso aos alunos de inclusão durante esse período de afastamento e favorecer os processos inclusivos.

Loureiro e Lopes (2015) mencionam que capacitar o maior número possível de pessoas para o uso das Tecnologias Digitais (TD) confere importância aos programas de disseminação das TD na educação pública escolarizada. Contudo, ressaltam a necessidade imperativa de variadas ações - de responsabilidade dos governos - para que todos aqueles que estão diretamente envolvidos nesse processo - estudantes, docentes, profissionais da educação - alcancem essas tecnologias:

[...] apenas a capacitação de recursos humanos não é suficiente; é preciso que essa ação esteja atrelada a outras, como a distribuição de computadores, a produção do desejo pela internet, a aprendizagem em todos os espaços, a conexão em rede e a disponibilidade para acessar e ser acessado (LOUREIRO E LOPES, 2015, p. 373).

Os resultados da pesquisa realçam a importância da escola presencial em todos os âmbitos: social, econômico e cognitivo. Também mostra aspectos positivos e negativos do ensino remoto adotado no Estado do Rio Grande do Sul. Constatamos que a 
ducação física e aulas remotas: um olhar para o trabalho com alunos com deficiência... Caroline Maciel da Silva • Roseli Belmonte Machado • Denise Grosso da Fonseca

aula presencial disponibiliza alternativas que o ensino remoto não oferece, principalmente nessa disciplina, como: atividades práticas com a supervisão de um professor/a, a interação social entre professor/a-aluno/a e aluno/a-aluno/a a troca de experiências que podem facilitar o processo de aprendizagem e de inclusão.

Chicon (2013), ao abordar a importância da inter-relação e da socialização entre os alunos e alunas de inclusão e o meio, quando das aulas presenciais, afirma que há:

Aproveitamento do uso dos órgãos sensoriais, diferenciando-os; aumento da estabilidade emocional e, em consequência, da autoconfiança; estimulação cognitiva, pela prática da orientação, da concentração, da reflexão e da memória; possibilidade de apresentar suas próprias necessidades, limitações e capacidades para os outros; socialização, por meio da cooperação, da participação, dos conflitos e das soluções; apropriação da cultura, pela descoberta das regras do jogo e, por extensão, das regras do comportamento social (CHICON, 2013, p. 27).

Importa destacar que, ainda que identifiquemos a falta de comunicação e de orientações iniciais por parte dos Governos, percebemos que as escolas se mostraram muito preocupadas com os estudantes, criando formas de contato, de manutenção do vínculo e claro, do ensino e aprendizagem. Formas que, muitas vezes, se mostraram tão novas para os professores e professoras quanto para os alunos e alunas.

Em relação ao nosso objetivo para esta análise, notamos que o professorado de Educação Física do Rio Grande do Sul tem criado estratégias de ensino para os alunos de inclusão, apesar de todas as dificuldades que se encontram no caminho, como a falta de estrutura para as aulas remotas e o distanciamento dos alunos. Diante dessa realidade, os alunos e alunas de inclusão, majoritariamente, estão sendo atendidos com atividades adaptadas, que são encaminhadas para as famílias, conforme as plataformas disponíveis e as necessidades de cada um. Compreendemos as difi- 
ducação física e aulas remotas: um olhar para o trabalho com alunos com deficiência...

Caroline Maciel da Silva • Roseli Belmonte Machado • Denise Grosso da Fonseca

culdades do processo e que estamos falando de uma in/exclusão, todavia, destacamos o trabalho dos docentes na busca para que o ensino da Educação física nas aulas remotas possa chegar aos mais diferentes alunos.

Reiteramos a necessidade de toda a comunidade escolar refletir sobre os processos de inclusão, para que ela não fique restrita a seguir leis e diretrizes. Esperamos que as diferenças estejam presentes nos contextos escolares e passem a ser percebidas como potencializadoras do desenvolvimento humano.

\section{Referências}

BRASIL. Constituição da República Federativa do Brasil:

Imprensa Oficial, 1988. Disponível em http://www.planalto.gov.br/ ccivil_03/constituicao/constituicao.htm. Acesso em 29 jul. 2020.

BRASIL. Lei no 8.069, de 13 de julho de 1990. Dispõe sobre o Estatuto da Criança e do Adolescente e dá outras providências. Diário Oficial [da] República Federativa do Brasil, Brasília, DF, 16 jul. 1990. Disponível em: http://www.planalto.gov.br/ccivil_03/leis/ I8069.htm.Acesso em: 29 jul. 2020.

BRASIL. Presidência da República. Lei n. 9.394/96. Lei de Diretrizes e Base da Educação Nacional - LBDEN. Brasília, 1996. Disponível em: https://www.planalto.gov.br/ccivil_03/Leis/L9394. htm Acesso em: 30 jul. 2020.

BRASIL. Presidência da República. Lei no 13.146. Lei Brasileira de Inclusão da Pessoa com Deficiência (Estatuto da Pessoa com Deficiência). 2015. Disponível em: http://www.planalto.gov.br/ ccivil_03/_ato2015-2018/2015/lei/l13146.htm. Acesso em 31 jul. 20. BRASIL. Ministério da Educação. MEC/SECADI. Política Nacional de Educação Especial na Perspectiva da Educação Inclusiva. Brasília, 2014. Disponível em http://portal.mec.gov.br/index. php?option=com_docman\&view=download \&alias=16690-politica- 
ducação física e aulas remotas: um olhar para o trabalho com alunos com deficiência... Caroline Maciel da Silva • Roseli Belmonte Machado • Denise Grosso da Fonseca

-nacional-de-educacao-especial-na-perspectiva-da-educacao-inclusiva-05122014\&ltemid=30192. Acesso em 30 jul. 2020.

BOTTENTUIT JUNIOR, J.B.; ALBUQUERQUE, O.C. Possibilidades para o uso do WhatsApp na Educação: análise de casos e estratégias pedagógicas. In: Anais do I Simpósio Nacional de Tecnologias Digitais na Educação. Universidade Federal do Maranhão. Disponível em http://tecedu.pro.br/wp-content/ uploads/2017/02/Art16-vol18-edi\%C3\%A7\%C3\%A3o-tematica-III-ISNTDE-2016.pdf. Acesso em 11 ago. 2020.

BUENO, J. G. Crianças com necessidades educativas especiais, política educacional e a formação de professores: generalistas ou especialistas. Revista Brasileira de Educação Especial, cidade, vol. 3. n.5, 7-25, 1999.

CHIZZOTTI, A. Humanismo, Educação e Tecnologia. Revista e-Curriculum, São Paulo, v.18, n.2, p. 489-500 abr./jun. 2020. FOUCAULT, M. Segurança, Território e População. SP: Martins Fontes, 2008.

GIL, A. C. Métodos e Técnicas de Pesquisa Social. 6 ed. São Paulo: Editora Atlas S.A., 2008.

LOPES, M. C. Inclusão escolar, currículo, diferença e identidade. In: LOPES, Maura Corcini; DAL'IGNA, Maria Claudia (org.). In/ Exclusão nas tramas da escola. Canoas: Ulbra, 2007, p. 11- 33. LOUREIRO, C. B.; LOPES, M. C. A Condução Eletrônica Das Condutas: A Educação Como Estratégia De Disseminação De Práticas. Educação em Revista, Belo Horizonte, v.31, n.03, p. 359-378. jul. /set. 2015.

MAGNO, G. Financeirização da educação e EAD em tempos de pandemia. Sindicato dos Professores do Distrito Federal (SINPRO-DF). Brasília: SINPRO-DF, 2020.

MATTOS, S. M. N. A afetividade como fator de inclusão escolar. Revista Teias: Rio de Janeiro, ano 9, n 18, p. 50-59. jul. /dez. 2008. 
ducação física e aulas remotas: um olhar para o trabalho com alunos com deficiência... Caroline Maciel da Silva • Roseli Belmonte Machado • Denise Grosso da Fonseca

MELCA, F. M. A.; FERREIRA, G. F. Um Laboratório De Educação A Distância Para Pessoas Com Necessidades Especiais (IBC-LED). Revista Instituto Benjamin Constant. Rio de Janeiro, v. 1 n. 32, p. 1-15. 2005.

NACIF, M. F. P. et al. Educação Física Escolar: Percepções do Aluno com Deficiência. Revista Brasileira de Educação Especial. Marília, Sulina, 2010.v. 22, n. 1, p. 111-124, jan./mar., 2016.

NOGUEIRA, M.A.N.; RESENDE, T. F. A Pandemia e os Reveses Educacionais. Blog Pensar a Educação, Pensar o Brasil, Belo Horizonte, 04 mai. 2020. Disponível em https://pensaraeducacao. com.br/blogpensaraeducacao/a-pandemia-e-os-reveses-educacionais/. Acesso em 10 jun. 2020.

RIO GRANDE DO SUL. Distanciamento controlado. Educação. Primeiros Passos. Porto Alegre, 2020. Disponível em https://estado.rs.gov.br/upload/arquivos//distanciamento-controlado-educacao.pdf. Acesso em 30 jul. 2020.

SHIMAZAKI, I. M.; MENEGASSI, R. J.; FELLINI, D. G. N. Ensino remoto para alunos surdos em tempos de pandemia. Práxis Educativa, Ponta Grossa, v. 15, e2015476, p. 1-17, 2020. Disponível em: https://revistas.apps.uepg.br/index.php/praxiseducativa/article/view/15476/209209213432

\section{Publisher}

Universidade Federal de Goiás. Faculdade de Educação Física e Dança. Publicação no Portal de Periódicos UFG. As ideias expressadas neste artigo são de responsabilidade de seus autores, não representando, necessariamente, a opinião dos editores ou da universidade. 